\title{
When Language and Culture Interfere: Sexual and Reproductive Health of Migrant Women in the Coastal Region of Slovenia
}

\author{
Zorana Medarić \\ Science and Research Centre Koper and University of Primorska, Slovenia \\ zorana.medaric@zrs-kp.si
}

Mateja Sedmak

Science and Research Centre Koper, Slovenia

mateja.sedmak@zrs-kp.si

\begin{abstract}
The aim of this chapter is to present and discuss the field of reproductive health of migrant women, with emphasis on the perspectives of migrant women and healthcare professional (doctors, midwives, community nurses, etc.) on existing practices, intercultural differences, access to reproductive healthcare services, etc. Within the chapter we discuss the results of the qualitative study and in-depth interviews that were implemented in the coastal region of Slovenia. The chapter presents different issues that emerged from the study, focusing on: (1) language barriers, (2) intercultural competencies of healthcare professionals, (3) (hidden) discriminatory practices/attitudes of medical personnel, (4) information and access of migrant women to health services and (5) the importance of social ties for the reproductive health of migrant women. Finally, the article proposes some guidelines for further action in this area.
\end{abstract}

\section{Introduction}

In this chapter we address the complex topic of the reproductive and sexual health of migrant women, with special emphasis on the personal experiences and perceptions of migrant women and healthcare professionals. This is an area that has rarely been researched in Slovenia. In the existing studies on migrants and the health system, the issue of migrant women has been addressed only indirectly; they are exposed as a vulnerable group which should be given special attention in this context. While none of the studies addressed the narrow area of the reproductive health of migrant women, there has been some research in the topic of general access to medical care for migrants. The results of these studies (Jazbinšek \& Palaić, 2009; Bofulin \& Bešter 2010; Rajgelj, 2012; Lipovec-Čebron, 2009, 2010, 2017) indicate that migrants within the health system in Slovenia are faced with various problems, 
among which the key issues are (1) language barriers, (2) lack of intercultural competencies of health professionals and (3) discriminatory attitudes and practices of health personnel towards migrants. These are also three of the main topics we consider in this chapter. In addition, we focus on the following two issues: (4) information and healthcare services access, and, finally, (5) the social ties of migrants and their relevance for the reproductive health of migrant women. Similarly, current research abroad focusing on the sexual and reproductive care of migrant women highlights linguistic challenges and the importance of providing relevant information (e.g. Zelalem, Janette, Tinashe, \& Ussher, 2018; Villadsen, Mortensen, \& Nybo Andersen, 2017; Small et al., 2014) and adequate access to healthcare services (Keygnaert et al., 2013). Villadsen et al. (2017), who researched this issue in Denmark, suggest that the key challenges in ensuring quality healthcare in the area of reproductive health are the inadequate use of interpreters and difficulties in intercultural communication. Small et al. (2014), who compared the experiences of maternity care of migrant women and non-migrant women, found that migrant women have less positive experiences, primarily due to problems related to communication, their perception of discrimination as well as disrespectful, unkind care, and lack of information about how the health system works. As presented below, similar obstacles and challenges are observed in our research.

Slovenian Constitution guarantees the right to healthcare for everyone and the freedom of choice in childbearing. In Slovenian legislation, reproductive health is regulated by the Health Measures in Exercising Freedom of Choice in Childbearing Act ${ }^{1}$ and the Rules on Carrying out Preventive Health Care at the Primary Level. ${ }^{2}$ The Act stipulates the conditions for exercising the right to prevent conception, artificial interruption of pregnancy and the diagnosis and treatment of reduced fertility, while the Rules specify the reproductive health rights and the content of preventive programs. Despite the fact that migrant women are recognized as one of the most vulnerable social groups in the context of reproductive health, they are not explicitly mentioned either in the law or in the regulations.

What follows is the presentation of the results of the qualitative research carried out as a case study in the border region of the three coastal munici-

\footnotetext{
${ }^{1}$ Zakon o zdravstvenih ukrepih pri uresničevanju pravice do svobodnega odločanja o rojstvu otrok, see http://pisrs.si/Pis.web/pregledPredpisa?id=ZAKO408.

${ }^{2}$ Pravilnik za izvajanje preventivnega zdravstvenega varstva na primarni ravni, see http://www .pisrs.si/Pis.web/pregledPredpisa?id=NAVO59.
} 
palities (the Municipality of Koper, the Municipality of Izola and the Municipality of Piran) (Sedmak et al., 2018a, 2018b, 2018c). The survey was carried out as a part of INTERREG cross-border project INTEGRA: Cross-border Network for Immigrant Women: Social Integration, Sexual and Reproductive Health, which takes place in Slovenia and Italy. We will present the five topics mentioned above, each of them affecting the reproductive and sexual health of migrant women in Slovenia, namely language and communication issues, intercultural competencies of health professionals, discriminatory behaviour and practices of health professionals, information and healthcare services access, and the importance of social ties for the reproductive health of migrant women.

\section{Methodology}

The implementation of semi-structured interviews within the case study of the coastal area took place between May and August 2018. Three health centres were included in the study, namely Health Center Koper, Health Center Izola and Health Center Piran, as well as Izola General Hospital. Ethical approval of the research was obtained by each institution. The survey was carried out among the health centre staff of the community nursing service and gynaecology clinics, and at Izola General Hospital at the Department of Obstetrics and Gynaecology. In this context, 18 semi-structured interviews with health professionals in the field of sexual and reproductive health were conducted, namely three in-depth interviews with gynaecologists (health centres and hospital), four interviews with midwives in the maternity ward, two interviews with nurses in the maternity ward and three group interviews with nine community nurses (HC Koper, $\mathrm{HC}$ Izola and HC Piran). A telephone conversation with a pro bono clinic in Ljubljana was also conducted and information on the pro-bono clinics in Koper was obtained from the management of $\mathrm{HC}$ Koper. All interviews with medical staff were carried out with prior personal consent and with the permission of the health institution concerned; they were carried out at workplaces and lasted between one hour and one and a half hours. Interviews were recorded and transcribed. In the period mentioned, eight in-depth interviews with migrant women from India, the Philippines, Ukraine, Russia, Thailand, Indonesia, Azerbaijan and Bosnia who live in the area of the three coastal municipalities were also conducted. $^{3}$ For a better understanding, it should be highlighted that the area

\footnotetext{
${ }^{3}$ In order to protect their anonymity, the statements given by the interviewees (in the chapter Findings) do not contain information about their characteristics, such as ethnicity, age etc. The
} 
of the case study is markedly multicultural. In addition to the presence of an autochthonous Italian minority, immigrant communities from the former Yugoslavia (Bosniacs, Albanians, Serbs, Croats, Macedonians, Montenegrins) are mostly present in the study area. They are very visible in everyday life and organized in the form of various cultural societies or religious communities. In addition, Russian, Chinese and Thai ${ }^{4}$ communities are also noticeable, while members of other ethnic groups are present, but, as an ethnic community in the local environment, largely unrecognized. The interpretation of the obtained results is interesting in light of the fact that, according to previous research, the area of Slovenian Istria is relatively more interculturally tolerant, meaning that in comparison with other Slovenian regions, members of other cultures, religions and languages are more accepted and there is less widespread xenophobia and nationalism (Sedmak, 2003, 2005). Finally, the proportion of ethnically mixed families is the highest in Slovenia (September 2006).

Although the results presented below refer to 'migrant women' as a particularly vulnerable group, which, as mentioned above, needs special care and treatment in the field of sexual and reproductive health, we must be particularly careful to avoid the following perceptions of migrant women (omnipresent in the medical field, in science and among the general public):

1. Migrant woman as a homogeneous group. Migrant women are a highly internally differentiated social group, according to cultural, religious and linguistic characteristics, as well as other indicators that have a key influence on the quality of their lives in terms of their ability to integrate into new social environments, access to health and other services, support networks, etc. There exist differences in terms of education, socioeconomic status, cultural capital and the causes of emigration, past life experiences, individual health situation, psychological characteristics and others. Although it is possible to draw certain parallels between the life stories and narratives of migrant women and draw some common conclusions, there still exist important differences among them.

2. Perception of migrant women as helpless, passive and victims of either

women interviewed differ according to the level of education, employment - some of them are employed, while some are housewives. They all have children and they are all married or live in a partnership, except one, who is divorced. Few have Slovenian citizenship, most of them have a status of foreigner with permanent residence in Slovenia.

${ }^{4}$ Particularly because of ethnically branded shops, restaurants or other activities (such as Thai massage salons). 
their husband, the wider family, ethnic community or external circumstances. Again, it is true that migrant women are an extremely vulnerable social group, often facing double discrimination (as women and as migrants), but they are also much more than that. They are active cocreators of their lives. Their activity, ingenuity, adaptability and perseverance are evident from their life stories, which speak of leaving their homeland, immigration to a new country and adaptation to a new, often completely different, cultural and social environment.

\section{Findings}

\section{Communication and Language Barriers}

(Successful) communication between the migrant woman and healthcare staff is crucial and has a significant impact on their satisfaction with medical care, understanding of their own state of health, coping with pregnancy, giving birth, postnatal care, as well as any illness, etc. It might also affect adherence to the instructions of medical staff (in our case the instructions of midwives, gynaecologists, community nurses, etc.) (Bofulin \& Bešter, 2010). In Slovenia, interpretation within the health system in the field of sexual and reproductive health is not systematically regulated, even though language barriers represent one of the central problems in ensuring quality reproductive healthcare for migrant women.

In the case of migrant women who do not speak Slovenian, it is crucial that both they and gynaecologists, midwives, nurses and other health professionals speak English, Italian or Croatian/Serbo-Croatian/Serbian.

Language was never a problem, because at least doctors speak English; when I started to speak a little Slovenian and explained, it was even easier.

If a migrant woman does not speak Slovene, a person speaking the Slovenian language often assists with interpreting. This might be her husband, a relative, a neighbour, a friend or an interpreter selected by the ethnic community (for example, the Albanian community in Koper and Izola).

When I come to the family, where they do not understand Slovenian, I always ensure that there is someone there who understands; the firsts visit especially are really important.

The husband can be present at the birth, he is translating; sometimes they bring along an interpreter. If she is alone, we need to be ingenious, 
you show them [...] For me in the delivery room this is not a big problem, because usually they have a companion, they have a part of home with them. When they are at the hospital department, they are a little more isolated. They do not have anyone near, they are alone. But I noticed that often they have a telephone and then they communicate in a way that they do not feel alone.

According to the narratives of health professionals, a particularly vulnerable group of migrant women are Albanians, who usually do not speak Slovenian, English or any other language.

They are from Kosovo, Albania, Macedonia, they do not speak Slovenian; usually the husband translates but he speaks Slovenian poorly. As a rule, they do not speak English.

Resolving communication problems is therefore left to individual health professionals and their ingenuity. They try to solve them with ad hoc interpreters (e.g. a husband, relative, neighbour, friend or an ethnic community translator), technology (cell phones), brochures, non-verbal communication.

Sometimes midwives asked a husband to tell us a couple of words, so we made a dictionary, so at the end of the delivery at least you can tell her that she should breathe, push.

Communication is sometimes such a problem that even Google translate does not help, or that book from the Ministry that they have given us, so that we are actually distressed, because we don't know whether they hear us, if they understand. And there is a greater possibility that we overlook something.

The lack of language knowledge and the inability to fully communicate has various implications. One of the main problems is that as a result some migrant women are actually excluded from prenatal and postnatal care: they do not attend maternity schools, courses, workshops, lectures, etc.

Language knowledge is the problem. And again, here we are, they cannot attend maternity school if they do not know the language [...] We have the right to visit the pregnant woman in the last trimester, but we do not get the data [about the women who are at this stage, ZM] and those who come to maternity school are already informed. [...] So, we 
could at least prepare them, give them specific information. When we come to their home, we do not have anything to 'grip on.'

Inadequate communication is problematic for both health centres and the hospital employees.

And they are in distress; not only them - we are too. Not only does a husband translate and filter information, but sometimes older children are even translating, which is absolutely inappropriate, but this is what we have. Sometimes they organize themselves, at least those who have been here for a longer time or those who stay here, they bring along a neighbour or someone, who has been here for a longer time to be an interpreter.

In addition to the distress of migrant women and health staff, the issue of possible (professional) mistakes due to communication problems has been raised. According to both migrants and health professionals, one of the ways to improve intercultural communication would be the inclusion of a cultural mediator at a systemic level, who could be shared by several community nursing services or could be contacted by a maternity hospital, a gynaecologist, etc. In their view, the cultural mediator should be a woman with specific medical knowledge and should be 'independent' - not a member of a local ethnic community.

\section{Intercultural Differences and Intercultural Competencies}

The concept of intercultural competencies highlights the importance of taking into account the linguistic, cultural and religious specifics of migrants who are being treated within the Slovenian health system. In our case study we could observe two broad approaches of health professionals: the first could be called (1) an interculturally aware approach, according to which health professionals recognize intercultural differences in the thinking and practices of migrant women as well as the functioning and significance of traditional cultural practices. These professionals do not adopt an institutional position of power in their approach to intercultural differences, and they allow traditional practices as long as these do not interfere with prevailing medical doctrine and do not directly harm the woman and/or the child.

They have this cradle [...] it looks as if one big tube was cut in half. And then they wrap newborn babies from the neck to the heels, and they stay in this cradle for four hours. And when I came to visit for the first 
time, I was shocked, but I said to myself, that's the way they do it. If the newborn is gaining weight, if the skin, the mucosa ... if it is pink, as it should be, then I have no right to interfere with their decision about how they will handle this newborn. I just told them and advised that after a few hours, when they decide to unwrap the newborn, they should put him on a bed or sofa so that he can move around a bit. [...] I think it is right if this is their system of life, a belief; we cannot oppose it, no. I do not have the right. I can advise, but not absolutely refuse or advise against something.

The second approach suggests the presence of cultural and ethnic prejudices and stereotypes, the process of exoticization, 'differentiation,' as well as nationalism and interethnic intolerance; this is (2) an interculturally unaware approach. Healthcare professionals see certain traditional practices of migrant women or their attitude towards birth control, the presence of patriarchal patterns etc. as errant.

I'm very annoyed by that rocking [rocking the cradle, MS], which is so striking. I once allowed myself to put a diaper around newborn's head, because that head was moving around as if you were ventilating his brains [...] Once he had a handkerchief on his face. They have wipes or handkerchiefs for their faces.

The narratives of migrant women show the other side of the same problem: the lack of intercultural competence or intercultural empathy of health professionals involved in work related to sexual and reproductive health, as well as within the Slovenian health system generally. For example, for a migrant from Asia the first gynaecological examination in Slovenia was very unusual, at times torturous and completely contrary to expectations:

- She missed the privacy: in the health centre clinics she had to remove her clothes and walk naked past the table to the other end of the room where the gynaecological chair stood. She would have liked to have a cape, a towel, anything that would make it possible for her to cover herself. She felt unnecessarily vulnerable, exposed, also ashamed. [Privacy and personal dignity problem]

- She did not like the approach of the gynaecologist who did not inquire about her health, medical history, contraception, childbirth, but immediately started the examination without explaining what she was doing and why. [Problem of medical staff approach] 
- She was disturbed by the absence of a nurse and the fact that she was alone with a gynaecologist. [The problem of gender relations]

Another immigrant woman from Asia describes a negative experience that relates to her delivery. She comes from an environment where the birth of a child is a 'less formal and more social event', involving more people from the community. If she gave birth in her place of origin, according to her testimony, a village woman who was trained to help with childbirth and one of her female relatives, her mother or sister, would all be present at birth. Even the birth itself would, in her opinion, be done differently. A midwife would massage her, massage her baby, and she would lead her through the birth in a different way. The birth protocol in Slovenian hospitals can therefore be a real culture shock for migrant women and a very unpleasant experience.

Giving birth, I really wanted my husband to be with me, I explained my nurse: 'Please call my husband!' But my husband was not there. I was so sad. [She started to cry, MS] The worst thing was that you were alone in the room, there were not many patients, no mothers, no doctors, no nurses, and I was: OK, who I could call? I can call my mother, my father, at home, and in my mind it was, oh no, it is too expensive [...] That was the worst.

Some women also pointed out that they wanted to have a woman gynaecologist, but most had no choice.

I wanted a female gynaecologist. There is no way I coud go to a man. At 22.

In recent years, intercultural competencies in Slovenian healthcare have been given a little more attention - for example, in the form of a pilot scheme for training health professionals in this area, the provision of cultural mediators by non-governmental organizations in individual institutions and other similar actions - but there still exists much potential for improvements in this area.

\section{Ethnic Stereotypes, Ethnic Prejudices, Nationalism, 'Racism' and Discriminatory Practices in Relation to Migrant Women}

Although medical staff are formally committed to acting in the patient's best interest, forms of discriminatory treatment can be observed in our interviews. This is sometimes more and sometimes less explicit. Health personnel are not 
immune from ethnic prejudices, stereotypes, culturalism and other forms of discriminatory behaviour. The most explicit expression of negative attitudes towards migrant women (as well as migrants in general) was expressed by one of the health professionals. He is against immigration and expressed the view that migration should be limited or prohibited completely. He also pointed out that 'with these people I don't have anything in common.'

You call me a nationalist, a chauvinist, a racist. I don't care. This is my opinion. Of course, you as a sociologist, you think differently.

Particularly in relation to Albanian women, among healthcare professionals there is a very firm and stereotyped belief that Albanian women: do not speak Slovene; are under the control of the husband and the wider family; are not emancipated, but are isolated, ignorant, poor, and do not want to integrate, etc. In short, they are seen as a homogeneous ethnic group without internal differentiation. In attitudes towards them, compassion (they are perceived as helpless victims of their own culture) and victimization (they do not want to speak Slovenian and do not want to integrate into Slovenian society) can simultaneously be observed.

These are women who are in a closed circle, who usually do not make contact, do not go to the store, do not go to meetings, do not go to kindergarten, unlike all these other immigrants that we also have. Let's say the Russians recently, who want to integrate. Maybe they have a different interest.

If you have our insurance, come with our insurance, by staying here, excuse me, but for every country that you go to, you should do the training course, the basic language. I mean three words: bleeding, pain, I can't do it anymore, breast, milk ... and goodbye - that's it. Nobody asks you for anything special. They look at you stupidly, do not know, they do not know. At 2 pm 'my husband.' Well, what is the matter with you? I am a midwife, I am not a multinational, not even on television, nor do I know how to say it [...]

A special form of difference - behaviour based on 'exoticism' - was experienced by one migrant woman. According to her, this was not offensive, more a mixture of 'affectionate treatment' and fascination over 'differentiation.' Her chosen gynaecologist addressed her with words like 'my little chocolate' and 
'my little darky.' Despite the fact that she points out that it did not bother her, it is necessary to draw attention to the problem of these forms of address.

Some migrants highlight the discriminatory behaviour of healthcare professionals towards migrant women.

When I gave birth, it was a little bit problematic for me too, the nurses, I think they were racists, some of them. You cannot avoid it, so for me it was $\mathrm{OK}$, as long as you are doing your job. As long as you are treating me as the others, it is not necessary to talk with me. I see that some of them are like that. You noticed it. And not only me, also towards other women who come from different countries.

As presented below, discriminatory behaviour is often based on visual distinctiveness:

She behaved as if she was better than me [the nurse, MS], I felt that she was watching me. [...] She only sees a person from the outside. Then I told her that I was also a secretary that [...] that like her, I, know how to use a computer, I can work. Then she was quiet.

While migrant women also presented positive experiences, we exposed practices that are problematic because they violate the right to equal treatment in the Slovenian health system (defined in the Patients' Rights Act ${ }^{5}$.) - those that are based on unequal power positions and reproduce existing social relations on the axis of domination and subordination.

\section{Healthcare Access}

Despite the declarative universality of the right to healthcare, the inclusion or exclusion of beneficiaries of health services depends on their legal status. The Slovenian system of access to health services is based on health insurance, which means that migrants have access to health services if they are included in health insurance; otherwise, they will only be entitled to free emergency treatment. In this respect, the Slovenian system mostly protects regular employees and their family members with permanent residence in Slovenia (Rajgelj, 2012). Bofulin and Bešter (2010) highlight the existence of a gap between relatively well-regulated formal access to Slovenian healthcare and actual unimpeded access to quality healthcare. They identify one of the obstacles as the lack of information about the health system and the rights de-

${ }^{5}$ Zakon o pacientovih pravicah, see http://pisrs.si/Pis.web/pregledPredpisa?id=ZAKO4281 
riving from it. In this context, loannidi-Kapolou (2007) also highlights, among other things, health risks arising from lack of information. This was confirmed also by informants in our study:

I think migrant women do not care enough about their health because they are not well informed about the rights and opportunities they have. What often gets complicated is when they need to have medical checks, but they don't have a chosen general physician or a chosen gynaecologist, so that before discharge from hospital we talk about it and provide appropriate instructions for checking. Because a certain part of the treatment is carried out at home, it must be under control, under the supervision of either a general practitioner or gynaecologist.

Migrant women highlighted also the lack of information and, consequently, difficult access to (quality) health services. They do not have comprehensive and accessible information on the health system and other aspects of life in Slovenia in their own language or in a language they can understand.

As a foreigner, you do not have information [for example, who is a good doctor/gynaecologist, ZM], you start from scratch in Slovenia. You do not know anything, you do not have information in another language or a website that you can understand. [...] We need information for the school, for a health centre.

The statement of the informant, who informally translates from Russian, points to the importance of being informed about adequate access to health services, highlights that migrant women's access to health services is closely connected to their legal status, employment or a proper form of insurance, and, last but not least, emphasizes the importance of (informal) social ties in ensuring the (reproductive) health of migrants.

I translate for the Russians in Izola [Hospital, MS]. They call me. [...] One lady called me, how much would it cost to pay for the birth, if she would be self-paying - she was not insured, she was a foreigner. Is it better to become an independent entrepreneur and be insured through it or just pay for it? At that time, I found out all the information for her, they told me everything, they were very friendly. It is better for her to have insurance, they told me, and so she did.

Access to a health system, which is particularly important for migrant 
women (Ioannidi-Kapolou, 2007; Bofulin \& Bešter, 2010), is sometimes limited in Slovenia due to long waiting lists, which were often mentioned by the interviewees. The issue of access to health services in connection with the socio-economic status of migrants is highlighted here: those with a better economic status have access to private (and faster) health services.

I cannot have an ultrasound, 45 days is supposed to be fast - this is not fast for me, I need it now. If I have a problem, I need to know now [...] If I need anything, I go to the private doctor.

In the case of access to health services, it should be mentioned that in Koper there exists a pro bono clinic that operates once a week. Among other people, it is intended for migrants without regular status and therefore without insurance. There are few similar clinics in Slovenia that provide access for migrants without organized health insurance. In Koper there is no specialized gynaecological pro bono clinic, but there is one in Ljubljana and, according to the social worker who works there, it also receives a considerable number of visits. This suggests that such clinics are important for ensuring adequate access to health services for migrants without insurance and represent a protective network for this particularly vulnerable group of migrant women.

\section{Social Network and Reproductive Health of Migrant Women}

In ensuring their (reproductive) health, migrants' social networks play an important role. These are people who are trusted by migrant women, and who at the same time facilitate their integration into the new environment (Brovč, Ahčin, Šlajpah, \& Rotar-Pavlič, 2009); here both aspects are important - social ties in the environment in which they currently live as well as those from the country of origin. When migrating to a new environment, migrants are often confronted with personal distress and social isolation. The migrant community may play an important role in the process of adaptation as well as in obtaining information, etc. in relation to healthcare and specifically reproductive health. In this context, migrant women stressed the importance of information to facilitate choosing a doctor, a gynaecologist, information on health insurance and the organization of healthcare in general, as well as information on postnatal care.

I have friends here, from Indonesia, and what I can [I tell them, ZM] [...] they ask, I tell them [...] I go here [to this doctor, ZM]. 
Sometimes they seek gynaecologists who understand their language. I have a feeling that they will not attend maternity school, I have the feeling that any information she will want she would rather ask her colleague, sister, mother, father-in-law, mother-in-law, anyone more trusted. She knows she will get information there.

As previously mentioned, existing social contacts and social networks also play an important role in communicating with healthcare professionals, as in the case of a nurse visit at home after the birth.

Even if being involved in ethnic community can be a source of support to migrant women, including with regard to the access to health services, it may in some cases also present a restriction, in particular in terms of access to sexual and reproductive care by migrant women at the institutional level. In the following example, a healthcare worker sees the community as an inhibiting factor for joining a maternity school.

They are very strong as a community and they will not attend classes for future parents.

The migrant community can play an important role in providing assistance to women - for example, directly after giving birth, when they get support from other women, relatives or members of the ethnic community who help to care for her and the child.

But they also like to help. I had, for example, one house, there were three families in it, one in each room. They had a common kitchen, at the same time there was a bunch of children - you did not know from which door one came - but when she gave birth, all these girls helped her. They took care of her children, they looked after her.

On the other hand, women who are not integrated in the community and do not have additional help in the local environment can face social isolation and distress.

It was difficult for me when I had my first son. It was only me and XXX [husband, ZM] and XXX. She came to help, she is my husband's colleague. [...] In the Philippines everyone would help you, you call, they come - neighbour, friend ... here everyone is for themselves, you have to pay someone to watch your child ... when you go to give birth, for example. 


\section{Conclusions}

Migrant women, as shown in our case study, face unequal treatment, discriminatory practices and restrictions in access to adequate institutional healthcare in the field of sexual and reproductive health. The key challenges in this area are communication with healthcare professionals and lack of information, and consequently lack of adequate access to (relevant) health services. Poor information and lack of or inadequate communication between medical staff and migrant women may lead to social exclusion, marginalization and stigmatization of migrant women, and this may also encourage unequal power relations between the women and healthcare professionals. Ineffective and/or inadequate communication can ultimately lead to professional errors or problems with treatment or medical procedures. A further important problem is the lack of intercultural competencies of health professionals and a lack of systemic solutions which would address the needs of migrant women in the field of sexual and reproductive health.

In this view, an important aspect that should be addressed in the future is action towards the sensitization of healthcare professionals with regard to intercultural issues as well as discriminatory practices and behaviour, which would facilitate the healthcare of migrant women, as well as help to prevent misunderstandings and possible professional mistakes. There exists also the need to introduce additional (systemic) education in the field of intercultural competencies, whereby special attention in the context of sexual and reproductive health should be given to attitudes of migrant women towards the body, privacy and gender relations. A step in this direction is certainly taken with the recently published Handbook for the Development of Cultural Competencies developed by the National Institute of Public Health (Bofulin et al., 2016), which aims to improve sensitivity to cultural differences and to increase understanding and acceptance of diversity in society. The final goal would be the introduction of these principles at all levels of healthcare education. Good practices indicate that it would be necessary to introduce a cultural mediator in the health system who could have significant impact on the reduction of discriminatory practices and treatment. Systemic regulation of interpretation in the health system is also necessary, as the problem of communicating is currently left to the creativity of medical staff and migrants. It should be emphasized, however, that for proper communication interpreters should also have (at least basic) healthcare knowledge (Zelalem et al., 2018).

Another important issue is that of providing proper information about institutional aspects of the sexual and reproductive health of migrant women. 
Due to lack of information and poor language knowledge, migrants are often excluded from institutionally provided prenatal and partially also postnatal care. One of the possible solutions to the integration of migrant women into prenatal care would be the organization of maternity schools also in a foreign language (e.g. English and Albanian), or the introduction of an interpreter in maternity schools. Experiences elsewhere (e.g. Villadsen et al., 2017) show that, in order to ensure the equal treatment of migrant women, it is necessary to provide professional interpreters in maternity care, to establish trust between medical staff and migrant women and to provide information that will enable them to 'properly navigate through the health system' (p. 109), which can significantly reduce delays in providing healthcare and appropriate treatment. A holistic and inclusive approach to health policies to ensure adequate healthcare for migrant women, especially in the field of sexual and reproductive health, is an important future challenge for public health throughout Europe (Keygnaert et al., 2013).

\section{References}

Bofulin, M., \& Bešter, R. (2010). Enako zdravstvo za vse? Imigranti v slovenskem zdravstvenem sistemu. In M. Medvešek \& R. Bešter (Eds.), Državljani tretjih držav ali tretjerazredni državljani? Integracija državljanov tretjih držav $v$ Sloveniji (pp. 270-311). Ljubljana, Slovenia: Inštitut za narodnostna vprašanja.

Bofulin, M., Farkaš Lainščak, J., Gosenca, K., Jelenc, A., Keršič Svetel, M., Lipovec Čebron, U., Pistotnik, S., Škraban, Š., \& Zaviršek, D. (2016). Kulturne kompetence in zdravstvena oskrba: priročnik za razvijanje kulturnih kompetenc zdravstvenih delavcev. Ljubljana, Slovenia: Nacionalni inštitut za javno zdravje.

Brovč, M., Ahčin, J. Šlajpah, M., \& Rotar-Pavlič, D. (2009). Ekonomski imigranti v Sloveniji in njihova stališča o boleznih. Zdravstveno varstvo, 48(1), 26-32.

Ioannidi-Kapolou, E. (2007). Health barriers and inequities for migrants. In Y. Apostolopoulos, \& S. Sonmez (Eds.), Population mobility and infectious disease (pp. 41-54). New York, NY: Springer.

Lipovec-Čebron, U. (2009). Od kulture nezaupanja do selektivnega sočutja: prosilci in prosilke za mednarodno zaščito v slovenskem zdravstvenem sistemu. Časopis za kritiko znanosti, 37(235/236), 190-203.

Lipovec Čebron, U. (2010). The construction of a health uninsurant. People without medical citizenship as seen by some Slovene health workers. Studia ethnologica Croatica, 22, 187-212.

Lipovec-Čebron, U. (2017). Ko nujno postane nenujno: raziskovanje zdravstvenih vidikov migracije v Slovenije. Glasnik Slovenskega etnološkega društva, $57(1 / 2), 54-64$. 
Jazbinšek, S., \& Palaić, T. (2009). Zdravje - človekova pravica? Prosilke in prosilci za mednarodno zaščito. Časopis za kritiko znanosti, 37(238), 154-162.

Keygnaert, I., \& Guieu, A. 2015. What the eye does not see: A critical interpretive synthesis of European Union policies addressing sexual violence in vulnerable migrants. Reproductive Health Matters, 23(46), 45-55.

Keygnaert, I., Guieu, A., Ooms, G., Vettenburg, N., Temmerman, M., \& Roelens, K. (2014). Sexual and reproductive health of migrants: Does the EU care? Health Policy, 114(2/3), 215-225.

Rajgelj, B. (2012). Vpliv delovnopravnega, državljanskega in družinskopravnega statusa na neenako obravnavo v zdravstvenem zavarovanju. Zdravstveno varstvo, 51(1), 43-52.

Sedmak, M. (2003). Stališča mladih slovenske Istre do (med)kulturnih fenomenov okolja bivanja. Annales, Series historia et sociologia, 13(2), 405-424.

Sedmak, M. (2005). Social inclusion/exclusion of immigrant groups in urban Slovenia: The case of Istria. Ethnologia Balkanica, 9, 241-259,

Sedmak, M., Medarić, Z., Lenarčič, B., \& Gornik, B. (2018a). Report on demographic, social and economic characteristics of migrant women in Slovenia. Koper, Slovenia: Znanstveno-raziskovalno središče Koper.

Sedmak, M., Medarić, Z., Lenarčič, B., \& Zago, M. (2018b). Principali caratteristiche demografiche delle donne straniere in Slovenia e Friuli Venezia Giulia. Koper, Slovenia: Znanstveno-raziskovalno središče Koper; Trieste, Italy: Edizioni Università di Trieste.

Sedmak, M., Medarić, Z., Lenarčič, B., \& Gornik, B. (2018c.) Spolno in reproduktivno zdravje migrantk $v$ sloveniji: študija primera treh obalnih občin. Koper, Slovenia: Znanstveno-raziskovalno središče Koper.

Small, R. C. R., Manjri, R., Touran, S., Dineke, K., Maureen, H., McCourt, C., \& Gagnon, A. (2014). Immigrant and non-immigrant women's experiences of maternity care: A systematic and comparative review of studies in five countries. BMC Pregnancy and Childbirth, 14(152), 1-17.

Villadsen, S. F., Mortensen, L. H., \& Andersen, A. (2017). Care during pregnancy and childbirth for migrant women: How do we advance? Development of intervention studies - The case of the MAMAACT intervention in Denmark. Best Practice \& Research Clinical Obstetrics \& Gynaecology, 32, 100-112.

Zelalem, B. M., Janette, P., Tinashe, D., \& Ussher, J. (2018). Talking about sexual and reproductive health through interpreters: The experiences of health care professionals consulting refugee and migrant women. Sexual \& Reproductive Healthcare, 16, 199-205.

S. Ličen, I. Karnjuš, \& M. Prosen (Eds.). (2019). Women, migrations and health: Ensuring transcultural healthcare (pp. 155-171).

Koper, Slovenia: University of Primorska Press.

https://doi.org/10.26493/978-961-7055-43-6.155-171 